\title{
A transformação digital da escola de negócios das artesãs da rede ASTA em tempos de covid-19: inclusão e colaboração
}

The digital transformation of ASTA network artisans in times of Covid-19 period: inclusion and collaboration

\author{
Francisca Angélica de Oliveira ${ }^{1}$ \\ Fernanda Goulart da Silva ${ }^{2}$ \\ Yasmin Rizzo Soares ${ }^{3}$ \\ Fernanda Galvão Sklovsky ${ }^{4}$
}

\section{Resumo}

O presente artigo tem como objetivo apresentar um estudo de caso de aceleração da transformação digital pela pandemia do Covid19. Para tanto, foram pesquisadas 27 artesãs que compõem a Escola de Negócios das Artesãs da Rede Asta. Elas forneceram dados sobre os seus processos pessoais de transição e adaptação das suas respectivas participações na Escola (com os seus 4 pilares: educação, design, liderança empreendedora e mercado), que iniciou no formato presencial e migrou para um modelo $100 \%$ online em um curto espaço de tempo. As considerações finais, por ora, elucidam que o processo de transformação digital acompanhado de um modelo guiado de mentoria tem sido bastante efetivo e significante para o público estudado, de modo que seus negócios produtivos continuem a existir, resistindo e se transformando, diante dos desafios do cenário atual.

Palavras-chave: Artesanato, Aceleradora, Transformação Digital, Pandemia, Microempreendedora.

\begin{abstract}
This article aims to present a case study of accelerating digital transformation by the Covid19 pandemic. For this, 27 artisans that are part of Business School of artisans of the Asta network were researched. They provided data on their personal transition and adaptation processes of their respective participation in the School (with its 4 pillars: education, design, market and entrepreneurial leadership), which started in the face-to-face format and migrated to a $100 \%$ online model in one short time. For now, the final considerations, elucidate that the digital transformation process accompanied by a guided mentoring model has been very effective and significant for the studied public, so that their productive businesses continue to exist, resisting and transforming themselves, in the face of challenges of the current scenario.
\end{abstract}

Keywords: Crats, Accelerator, Digital Transformation, Pandemic, micro entrepreneur

\footnotetext{
1 Pós-graduanda em Educação e Tecnologia - Universidade Federal de São Carlos (UFSCAR) - Brasil. f.angelicaoliveira@gmail.com

${ }^{2}$ Bacharel em Turismo - Universidade Federal de Juiz de Fora - Brasil. sgoulart.fernanda@gmail.com.

${ }^{3}$ Tecnóloga em Logística - Universidade Estácio de Sá - Brasil. yasmin.rizzo.make@gmail.com

${ }^{4}$ Bacharel em Design de Produto - Universidade Luterana do Brasil - Brasil. f.skydesign@gmail.com
} 


\section{INTRODUÇÃO}

Esse artigo investiga como tem se dado o processo de aceleração da transformação digital com um grupo de 27 alunas da Escola de Negócios das Artesãs (a Aceleradora de Educação Empreendedora da Rede Asta) e tem como objetivo principal identificar quais têm sido os principais desafios nesse processo de adaptação, catapultado pela Pandemia do Covid-19.

Segundo o estudo de mercado do SEBRAE (2018) o artesanato no Brasil possui em média $R \$ 28$ bilhões por ano de faturamento, emprega 8 milhões de pessoas e vem crescendo a cada ano. Neste segmento onde $77 \%$ dos profissionais são mulheres, $60 \%$ têm essa atividade como principal fonte de renda, mas apontam ter dificuldades com a comercialização dos produtos e a falta de visão do mercado (DATASEBRAE, 2013). Apesar do crescimento desse segmento no mercado brasileiro, a maioria desses profissionais não possuem salário fixo, sendo remunerados apenas por produção e também não buscam a formalização: apenas $11 \%$ dos artesãos recebem salário fixo e 39\% possuem CNPJ (DATASEBRAE, 2013).

Diante do cenário atual de crise da pandemia, percebe-se que os empreendedores do segmento de artesanato (em sua grande maioria mulheres) são um dos grupos mais afetados. Segundo dados do SEBRAE (2020) pode-se analisar que o artesanato tem características muito marcantes quanto ao processo como vem sentindo os efeitos da crise agravada pelo Covid-19: dentre os 22 segmentos estudados na pesquisa, ele aparece em penúltimo no ranking quanto ao número de pessoas ocupadas na empresa atualmente: uma média de 2,3. Empatado com o segmento de beleza, em primeiro lugar, $73 \%$ dos respondentes afirmou não ter funcionários e no topo do ranking, 50\% dos artesãos respondeu não ter dívidas/empréstimos em aberto.

O artesanato também é o segmento que menos fatura, com $55 \%$ dos respondentes afirmando que a sua média mensal do faturamento, nos 6 meses anteriores ao início das medidas de restrições, era de até $\mathrm{R} \$ 6.000,00$ por mês. Todos estes dados denotam características de um segmento que está majoritariamente inserido em um contexto de Economia Familiar, sendo as artesãs, muitas vezes, matriarcas e empreendedoras que sustentam todo um núcleo, conforme conseguimos verificar no estudo de perfil das turmas que atendemos na Escola de Negócios das Artesãs. Os dados do SEBRAE (2020) apontam também que, neste momento de restrição de circulação de pessoas, os empreendedores artesãos responderam que $38 \%$ das suas empresas não conseguem funcionar, pois o seu negócio funciona só presencialmente; já $14 \%$ afirma que a empresa funciona, mas que ele não tem estrutura para usar tecnologias digitais (a média nacional é de 12\%); por fim, 39\% tem conseguido continuar as atividades da empresa fazendo isso utilizando ferramentas digitais.

Para sobreviver dentro de um cenário severo de crise como este que tem se desenhado, a Escola de Negócios precisou reformular toda a sua metodologia de modo que conseguisse atender às expectativas das artesãs, ao mesmo tempo em que as auxiliasse em seus processos de aceleração digital, permeando 4 pilares fundamentais: Educação, Design, Liderança Empreendedora e Mercado. Todos estes dados, em conjunto, corroboram com as análises que serão apresentadas neste artigo, onde, verifica-se que a imensa maioria das artesãs atendidas percebem na transformação digital da Escola uma oportunidade de que os seus negócios não parem de funcionar, 
apesar de todas as restrições (idade, gênero, classe social, logística, acesso à internet, políticas públicas, etc.) a elas sentenciadas.

A metodologia aplicada no estudo foi uma pesquisa qualitativa realizada com 27 mulheres que são alunas da turma atual da Escola de Negócios das Artesãs. Elas responderam ao formulário online "Pesquisa Acadêmica sobre Transformação Digital entre as Artesãs" com 14 perguntas, divididas em 3 seções: Perfil Social, Perfil Digital e Considerações Gerais sobre o tema da pesquisa. Apresentaremos, a seguir, os dados desta pesquisa, demonstrando como se deu esse processo de Aceleração da Transformação Digital em cada uma das etapas da Escola de Negócios e como as artesãs o assimilaram e provocaram mudanças sistêmicas, na prática.

\section{A ESCOLA DE NEGÓCIOS DAS ARTESÃS}

Segundo OLIVEIRA E OLIVEIRA (2019, p.2): “Os Negócios Sociais unem objetivos do segundo setor da economia (gerar lucro) e do terceiro setor (causar impacto social às populações carentes). " (OLIVEIRA \& OLIVEIRA, 2019, p.2). Na definição de YUNUS (apud LIMEIRA, 2018, p.2):

O negócio social tem de ser autossustentável, ou seja, gerar receita suficiente para cobrir as próprias despesas. Uma parte do excedente econômico é investida em sua expansão, enquanto a outra parte é mantida como reserva para cobrir gastos inesperados. Portanto, o negócio social é uma empresa que não envolve perdas e não paga dividendos, inteiramente dedicada à realização do propósito social. (apud LIMEIRA, 2018, p.2)

A Rede Asta é um negócio social que atua na economia do "feito à mão" desenvolvendo artesãs em empreendedoras. Há quinze anos no setor do artesanato, já experimentou diferentes modelos de negócios, tendo sempre como ponto principal a geração de renda para as artesãs envolvidas. A importância de uma metodologia que "empoderasse" essas mulheres, de modo que elas mesmas pudessem buscar novas oportunidades e canais de vendas, foi a premissa para criar, em 2015, a Escola de Negócios das Artesãs com os objetivos centrais de aumentar as vendas, melhorar produtos, criar posicionamento de marca, construir relacionamento com os clientes e transformar artesãs em empreendedoras. As principais etapas da Escola de Negócios das Artesãs compreendem os seguintes eixos:

EIXO

Educação
OBJETIVO PRINCIPAL

Ter todas as artesãs com visão de futuro e maior percepção como empreendedoras, incluindo aprendizado e presença online 
Design

Liderança

Empreendedora
Aplicar conceitos e elementos do design nos produtos já desenvolvidos pelas artesãs, marcando uma identidade visando melhoria e criação de produtos para o mercado contemporâneo

Criar e fortalecer micro redes de artesãs para que, juntas, possam através de uma metodologia específica, fortalecer os vínculos entre si e realizar trocas potentes entre pares

Tabela 1: Eixos da Escola de Negócios das Artesãs

Fonte: Autoria própria

Segundo dados da REDE ASTA (2020), em 5 anos, a Escola já impactou, através de uma linguagem e metodologia pedagógica personalizados, um público de 4.628 pessoas, atendendo artesãs de 200 negócios produtivos artesanais em cinco Estados do país, somando mais de mil horas de conteúdos lecionados.

Nove turmas foram formadas e uma ainda em execução (a que é objeto deste estudo) com diferentes formatos e metodologias pedagógicas, sendo: as quatro primeiras totalmente no formato offline (com as aulas acontecendo presencialmente e com material de apoio em Power Point), turmas cinco a nove no formato híbrido (com artesãs assistindo as vídeo aulas na Plataforma Asta em casa e realizando exercícios presencialmente) e a turma 10, com modelo $90 \%$ digital. Nesta última, o primeiro mês das aulas aconteceu no formato híbrido e, com a pandemia, as atividades passaram a ocorrer totalmente no formato online.

Atualmente, com as novas demandas apresentadas pela pandemia do Covid-19, revisitou-se todo o seu projeto político-pedagógico em plena execução das aulas da turma $\mathrm{X}$, onde as artesãs passaram a ter encontros da Escola pelo Zoom, conteúdos extraclasse em lives do Instagram da Rede Asta, além de utilizar ferramentas de apoio como o Mentimeter, Padlet, dentre outros, que serão melhor descritos nas etapas a seguir.

\section{EDUCAÇÃO}

Cada turma da Escola de Negócios é formada pensando nas características individuais de cada negócio produtivo. Portanto, no início de cada turma é aplicado um questionário diagnóstico (um raio-X do negócio, onde se analisa as práticas em relação à comercialização, produção, formalização, gestão de pessoas, empreendedorismo, segurança e qualidade de vida, gestão administrativa e gestão financeira) que é respondido por todos os negócios selecionados.

A partir das respostas é gerado um relatório que indica quantitativamente os pontos forte e de melhoria de cada grupo, bem como seu nível de maturidade empreendedora, que pode ser básico, intermediário ou avançado. Em suma, todos os 
relatórios são correlacionados em um único relatório e forma-se, assim, um exclusivo para turma, que irá nortear o que denominamos Trilha de Aprendizagem.

Esta trilha envolve todos os cursos necessários ao longo do projeto, para que as artesãs participantes desenvolvam sua mentalidade empreendedora, capacidade de gestão e tenham acesso às ferramentas específicas para facilitar suas vidas enquanto em empreendedoras. Isso posto, na turma $X$ temos 10 cursos contemplados e que estão sendo ministrados na sequência demonstrada na tabela 2 .

1- Inclusão Digital

2-Canais de Vendas

3-Controle

Administrativo

4- Vendas Online

5- Precificação

6- Parcerias em Rede

7-Controle

Administrativo

8-Modelos de Formalização

9- Canais de Vendas
Conhecer e utilizar ferramentas digitais com o intuito de facilitar a vida empreendedora das artesãs

Utilizar os 4 P's do Marketing para criar estratégias para o negócio e conhecer qual a persona de cada grupo

Aprender sobre gestão financeira controlando, assim, despesas e receitas do negócio

Aprender quais as melhores ferramentas para Vendas Online e estratégias para usá-las

Apresentação de Ficha Técnica e como utilizá-la

Falar da importância de parcerias para que o negócio se desenvolva

Criar o Regimento Interno do grupo

Conhecer os diversos modelos de formalização e qual mais se encaixa ao negócio

Conhecer 14 possíveis Canais de Vendas e escolher alguns para implementar no negócio 
10- Práticas de

Venda

Aprender a fazer negociação de vendas com os clientes

Tabela 2: Cursos ministrados para Turma $X$

Fonte: Autoria própria

Todos os cursos estão disponíveis através da Plataforma Asta, uma tecnologia que tem o objetivo de transformar artesãos brasileiros em empreendedores, conectar esses pequenos produtores para criar uma rede cada vez mais potente e assim valorizar o artesanato nacional.

Cada curso gera uma atividade para casa com a proposta que as artesãs coloquem os conteúdos ministrados em sala de aula em prática. A arte de aprender fazendo tem seu fundamento na Andragogia (do grego andros - adulto e agogus educar). Segundo MARTINS (2013, p.145):

A Andragogia corresponde à ciência que estuda as melhores práticas para orientar adultos a aprender. É preciso considerar que a experiência é a fonte mais rica para a aprendizagem de adultos. Estes, por sua vez, são motivados a aprender conforme vivenciam necessidades e interesses que a aprendizagem satisfará em sua vida. (MARTINS, 2013, p.145).

Todas as artesãs têm acesso direto à professora/ mentora para tirar dúvidas e todo esse processo de implementação é acompanhado através de mentoria online. 0 intuito da mentoria é acompanhar individualmente cada negócio produtivo, rever as atividades propostas para casa, revisar os conteúdos dos cursos, tirar dúvidas e alinhar estratégias individuais para o crescimento do negócio. Cada mentoria dura em torno de 1 hora e é feita na semana seguinte à aula e por vídeo chamada do WhatsApp. "Nesse instante só retorno positivo. Estou fora do País no momento e me sentindo totalmente integrada com a metodologia, qualidade das mentorias/aulas online. ", diz uma das artesãs participantes em uma das respostas ao questionário aplicado para esse estudo e apresentado detalhadamente ao final do artigo.

Ainda considerando os dados da nossa pesquisa, o contato com ferramentas digitais é totalmente novo e desafiante para as artesãs, $16 \%$ das entrevistadas têm dificuldade de baixar aplicativos e $38 \%$ passaram a assistir aulas através de aplicativos. No início das aulas, em fevereiro de 2020, precisamente no curso de Inclusão Digital apresentamos algumas ferramentas digitais que podem auxiliá-las para facilitar a gestão do negócio, onde, na ocasião, apresentamos o Pinterest como proposta de pesquisa para inspiração de criação de produtos, a Plataforma Asta já mencionada anteriormente e ferramentas do Google.

Esse contato com o mundo online estava começando a se fortalecer quando a quarentena começou e a partir disso tivemos que reformular toda a metodologia da Escola e como novo plano escolhemos as ferramentas: Plataforma Asta, para que assistam os conteúdos dos cursos antes das aulas; Zoom e seus diversos recursos, que permite a realização de reuniões online para às aulas; Padlet, um quadro/mural online colaborativo onde pode-se inserir qualquer conteúdo (link, fotos, vídeos, textos) 
utilizado para as atividades durantes as aulas; WhatsApp para comunicação geral, integração das artesãs e mentorias através de vídeo chamadas.

A principal barreira enfrentada para o processo de aprendizagem foi a dificuldade das artesãs em baixar e utilizar essas ferramentas digitais. Para facilitar essa aprendizagem, foram gravados diversos vídeos tutoriais através da tela do celular, além de prints da tela e explicações detalhadas sobre o processo de uso das mesmas, onde cada dúvida era respondida pelo Whatsapp ou por ligação telefônica.

Em tempos de isolamento social por causa da Pandemia, a melhor maneira de utilizar a internet é como nossa aliada, repassando o conhecimento empreendedor e formando rede entre as artesãs.

\section{DESIGN}

Sob o ponto de vista de PAZ (1991, p.51), no artesanato: "há um contínuo vaivém entre utilidade e beleza; esse vaivém tem um nome: prazer. As coisas dão prazer porque são úteis e belas [...] o artesanato é uma espécie de festa do objeto: transforma o utensílio em signo de participação" (PAZ, 1991, p.51).

A fase do Design era um dos momentos mais esperados pela maioria das artesãs dentro da Escola e por este motivo gerou grande dúvida em relação à efetividade da migração para o online. A capacitação em design é o momento do projeto onde elas exercem ao máximo seu ofício e sua arte. O produto é a materialização do seu histórico de vivências pessoais assim como seu patrimônio cultural e uma mudança no objeto implica uma mudança na pessoa que o fez. Por isso, toda uma técnica de aproximação é desenvolvida, visando tornar o encontro um evento de interesse mútuo e retroalimentador. O Artesão é soberano, ponto de partida e chegada de qualquer intervenção. A metodologia aplicada na capacitação em design visa fazer a diferença entre as ações comumente realizadas no setor como o empirismo e a unilateralidade. Todos estes princípios foram adaptados e integrados para uma nova forma de relacionamento online. Os objetivos específicos da área de design neste projeto eram os seguintes: Aplicar conceitos e elementos do design nos produtos já desenvolvidos pelas artesãs e criar ícones gráficos que identifiquem as belezas e singularidades da região, marcando uma identidade visual.

A primeira aula de Design na Escola foi uma introdução ao tema. A aula se dividiu em diversos momentos com explanações teóricas e visuais. Os temas abordados foram: Introdução ao Design, relações entre design e artesanato e introdução às diversas expressões s artísticas. Também foram exibidos vídeos inspiradores e didáticos sobre os temas e houve um bate-papo com a Designer gráfica do projeto. Introduzimos a ferramenta/aplicativo Google Arts e fizemos um tour virtual por alguns famosos museus. Como tema de casa as artesãs receberam a tarefa de escolher uma das 11 expressões de arte apresentadas como inspiração para desenvolver um produto e depois postar no Stories, da sua página do Instagram, contando sobre os motivos de suas escolhas.

A segunda aula de design online abordou 3 grandes temas: Iconografia, cartela de cores e macrotendências. Os temas foram apresentados através de fotos inspiradoras do território das próprias artesãs (região de São João da Barra) com intuito de fazer com que elas criem um novo olhar de orgulho e pertencimento, para agregar 
valor cultural e histórico ao produto artesanal. Elas interagiram muito e se emocionaram ao ver imagens que pertencem à vida delas e desta forma aconteceu uma identificação instantânea que fortalece o engajamento no desenvolvimento da coleção de produtos. Também foram apresentados cases de projetos de inserção de design no artesanato pelo Brasil para estimular e ilustrar a metodologia de como aplicar a iconografia local e inspirações no produto artesanal. No final da aula foi explicado e reforçado o passo a passo que elas deverão seguir para a criação da coleção de 3 produtos.

Depois de explicada a metodologia as artesãs foram divididas em grupos e fizeram um exercício de preencher e discutir sobre as ideias para sua coleção. Estas dinâmicas nas aulas online fazem com que seja possível criar vínculos mais próximos entre elas, algo que seria natural durante as aulas presenciais, mas que se torna mais difícil nas aulas virtuais.

A terceira aula de design online teve grande enfoque na importância da fotografia para divulgação e venda dos produtos na realidade atual. Em função das inúmeras limitações, todas artesãs perderam os seus principais canais físicos de vendas como feiras e eventos. O novo principal canal de vendas, automaticamente, virou o online. As artesãs foram incentivadas e desafiadas a melhorarem gradativamente suas fotos para comunicação interna com a designer, estrategicamente visando a futura divulgação. Muitas artesãs foram sendo capacitadas organicamente durante as mentorias, então, esta aula reforçou a importância crucial de elas terem consciência e determinação para fazer uma boa foto de produto. Foram apresentados conceitos e técnicas simples sobre como tirar uma boa foto de produto além de uma série de fotos/imagens feitas por artesãs em outros projetos para que o grupo fizesse uma avaliação.

O processo de mentoria em Design inicialmente não estava previsto para o projeto na versão presencial. A mentoria foi fundamental para viabilizar a criação de novos produtos sob orientação e acompanhamento da designer. As mentorias são feitas na semana seguinte das aulas com horários previamente marcados. Ela e se tornou uma espécie de aula particular, semelhante a uma consulta médica, pois, a partir do diagnóstico é que são tratadas as estratégias para criação da coleção de cada artesã. Neste momento são tratados e discutidos todos aspectos relacionados aos materiais, produtos, equipamentos, espaço físico, motivação e gerenciamento de tempo entre a artesã e a designer. Muita troca é feita através de fotos, vídeos, áudios e mensagens por escrito e o desenvolvimento individual varia muito conforme a personalidade de cada artesã. Após a primeira mentoria, o canal de comunicação do Whatsapp ficou aberto para qualquer tipo de troca sobre os projetos dos produtos.

Em função do momento delicado e sensível em geral, a designer optou por deixar este espaço livre independente do tempo utilizado nas mentorias, portanto é possível dizer que as artesãs estão recebendo "aulas particulares" de design durante toda esta fase da Escola. Por ser a primeira vez em que esta etapa é executada 100\% online, esta foi a melhor forma encontrada para entender o até então inédito processo de co-criação virtual atual e poder propor novas diretrizes para um futuro projeto nos mesmo moldes.

As artesãs já entraram na etapa de design capacitadas pela fase de Inclusão Digital. A maioria do grupo já estava bem familiarizada com as novas ferramentas de comunicação como Zoom e Instagram mas algumas foram evoluindo ainda durante esta 
etapa. Exercícios sobre posts, stories foram estimulados durante as aulas e também como dever de casa. A introdução de aplicativos como Pantone Studio para apoio na criação de cartela de cores foi extremamente bem recebido pelo grupo. Todas estas experiências tiveram um impacto enorme em cada uma das artesãs pois, na prática, conseguiram vivenciar uma expansão de consciência, conhecimento e possibilidades que só a tecnologia é capaz de proporcionar. Como resultado da pesquisa temos um percentual de (65\%) das artesãs confirmando que estão recebendo pela primeira vez este tipo de capacitação.

\section{LIDERANÇA EMPREENDEDORA}

A etapa de Liderança Empreendedora da Escola de Negócios das Artesãs se intitula "Círculo de Lideranças Empreendedoras". O Círculo se caracteriza por ser um espaço protegido, criado para fortalecer vínculos, promover a aprendizagem entre pares, desenvolver competências para a liderança e facilitar a abertura de oportunidades de negócio através da rede. As principais fontes de inspiração para a definição da metodologia do Círculo foram: metodologias de redes autogeridas de aprendizagem (como núcleos pré-existentes de grupos da Rede Asta, formação de hubs, Teoria $U$, etc); metodologias formadoras de redes de apoio e autoajuda (Alcoólicos Anônimos, Vigilantes do Peso, Tendrel, YPO e Entrepreneurs' Organization); metodologias de construção de confiança (Empatilhaço/Teatro do Sopro) e, por fim, metodologias de formação e manutenção de redes de negócio.

Um encontro de um Círculo pode acontecer de três diferentes maneiras: vínculo (com o objetivo de criar e fortalecer laços de amizade e confiança entre lideranças como base para relacionamentos duradouros), estudo (com o intuito de desenvolver novas competências e habilidades, ampliando o repertório de conhecimento) e prática (ampliando a capacidade de impacto da liderança e estimulando ações integradas a partir da rede).

Geralmente um encontro dura em torno de quatro horas e de modo presencial. Com as trocas, as artesãs acessam lugares, que as permitem desenvolver uma maior visão de si mesmas e do mundo. De um modo geral, pode-se resumir que o que acontece, genuinamente, em qualquer encontro do Círculo é a prática de cristalização da intenção, dando espaço a uma nova visão de mundo e, consequentemente, na maneira de liderar e empreender, conforme descreve SENGE (2020):

Imagine that this thread of your life it's been guiding you there's been present, is not from you in the narrow sense of my identity, myself as I would normally define it in my body, my persona, but it's something that's kind of comes from the larger universe that we are part of. But then it shows up, becomes evident or becomes accessible in very idiosyncratic ways it shows up in each of us. So just imagine that's always been there, it always will be there. It has no place to go so it's not born and dies. But there are stages in our personal or a persona journey, where we access different facets of it and that facets is what you could call a vision. (SENGE, 2020) 
A turma apresentada neste estudo participou de um encontro de vínculo, de modo ainda presencial, antes do isolamento social causado pela pandemia. Neste dia, as artesãs tiveram a oportunidade de realizar trocas entre pares, compartilhando momentos de vida, a partir de uma agenda guiada, com metodologia própria, que envolve empatia, espelhamento, presença, atenção plena e escuta ativa nos diálogos.

Com a pandemia, os encontros presenciais foram suspensos e a turma passou a se encontrar através do aplicativo Zoom, em duas turmas diferentes, com dez lideranças artesãs em cada. Diferente das outras etapas, o encontro do Círculo é exclusivo para as lideranças artesãs, logo, a adaptação ao espaço digital foi um pouco mais tranquila, visto que temos um número reduzido de pessoas por sessão e, principalmente, pelo fato de os tempos de falas serem cronometrados, respeitando-se a metodologia. Neste aspecto, percebe-se um grande benefício nos encontros serem online, pois a aceleração digital permitiu que outros sentidos fossem melhor desenvolvidos, do que quando os encontros eram presenciais: a escuta, por exemplo, é um deles. Quando não se está presencialmente, ouvir com atenção, demonstrar a escuta com a expressão corporal, faz toda a diferença para a conexão da turma e isto tem se dado de modo surpreendentemente eficaz no círculo no formato online.

Na pergunta do questionário sobre se elas já haviam participado de um grupo de mulheres, anteriormente, através de videoconferência, percebe-se que, para $39 \%$ das respondentes, foi a primeira vez que elas fizeram algo do tipo. Importante sinalizar que em várias respostas do questionário, as artesãs sinalizaram a falta que estavam sentindo dos encontros presenciais, mas também consideraram os encontros pela internet uma oportunidade de estarem minimamente próximas e presentes, trocando entre si, diante de um cenário tão traumático.

De fato, os encontros do Círculo de Lideranças Empreendedoras têm proporcionado trocas tão incríveis quanto às presenciais, apesar do formato totalmente diferente onde, por vezes, a internet pode ser um ambiente muito pouco afável. No entanto, no momento atual, se torna imprescindível de continuar acontecendo, pelo fato de fortalecer, a cada encontro, estas lideranças empreendedoras do feito à mão para lidarem com suas próprias questões emocionais, se fortalecendo para inspirarem novas visões em seus negócios pessoais ou em grupo.

\section{MERCADO}

A etapa de Mercado da Escola de Negócios das Artesãs foi pensada e planejada como um grande diferencial para esse projeto, trazendo uma profissional responsável pela dinamização do mesmo, cuidando da apresentação dos produtos e esforços de venda no mercado local. No processo inicial, tivemos como metodologia o estudo e mapeamento dos possíveis consumidores, tentando fazer com que o artesanato seja visto e valorizado muito além de um souvenir, conseguindo atender às demandas em maior escala e contemplar o mercado B2B. Foram realizadas visitas presenciais em alguns estabelecimentos do ramo hoteleiro e gastronômico da região, para contato inicial e apresentação do projeto, pleiteando possíveis parcerias futuras.

Com a nova realidade estabelecida devido à pandemia, todo e qualquer processo de mercado, na Escola, teve que ser migrado $100 \%$ para o universo online. Todos os contatos com empresas e clientes passaram a acontecer somente por telefone e via e- 
mail. Segundo dados da BROADCOM (2017) uma pesquisa divulgada em fevereiro de 2017 pela CA Technologies, que utilizou indicadores para medir o impacto da transformação digital na economia, aponta o Brasil em terceiro lugar entre os mais afetados pela tendência, se fazendo necessária a aceleração digital de todos os processos.

Com o Impacto da pandemia de coronavírus nos Pequenos Negócios, segundo dados do SEBRAE (2020) os artesãos, em geral, tiveram queda de menos $68 \%$ no faturamento semanal (vs. semana normal), tendo também $83 \%$ dos respondentes da pesquisa alegado que o seu faturamento mensal diminuiu. Destes, $49 \%$ respondeu que, com a crise, interrompeu o funcionamento das empresas temporariamente, $38 \%$ aderiu à venda via redes sociais e $13 \%$ iniciou participação em comunidades de interesse de seus clientes. Com a queda do turismo e o foco do consumidor em produtos essenciais, o segmento de Artesanato deve seguir apresentando forte queda, em um nível consideravelmente inferior ao pré-crise).

O Digital Business está crescendo e desempenha um papel cada vez mais importante na realidade dos negócios. Qualquer negócio tem de ser digital. E os que forem mais capazes de se distinguirem, maior probabilidade terão de vingar entre a enorme competição que se vive no mundo atual. Pensando nisso, participamos da FINCC 2020 (Feira Internacional de Negócios Criativos e Colaborativos) realizada em formato $100 \%$ digital pelo SEBRAE Paraíba e totalmente focada em capacitação e disseminação dos mais diversos tipos de conteúdos relacionados à economia criativa (segmentos como artesanato, cinema, moda, arquitetura, comunicação etc).

Segundo dados do FEIRAS DO BRASIL (2020) o evento teve 185 expositores e cerca de 131.698 acessos, com 35 países conectados. Foi um grande exercício, nos mostrando o quanto somos capazes de nos adaptar e adequar às novas circunstâncias e situações, possibilitando avaliação e estudo de um novo modelo de mercado para tentar propor e replicar na Escola de Negócios das Artesãs.

Ainda como esforço de ampliar a visibilidade do projeto e alavancar vendas, entende-se a importância de estar inserido no mundo digital, onde, desse modo, viabilizamos a criação do coletivo das artesãs da turma atual da Escola, titulado "Rede Criativa". Elas criaram um perfil profissional no Instagram, sendo vitrine de todos os produtos e atividades, onde a Escola oferece todo o suporte para administração, curadoria, divulgação e marketing, descritos nas etapas acima. O objetivo é que, com a criação do Coletivo, as artesãs, independentemente da Escola, consigam tocar um modelo de negócio promissor onde, juntas, poderão fazer a diferença no mercado local e alcançar novos horizontes.

\section{RESULTADOS}

A décima turma da Escola, intitulada "Rede Criativa" está localizada no entorno do município de São João da Barra, atendendo também a distritos como Atafona, Pipeiras e Açu, todos no Norte do Estado do Rio de Janeiro. Após coleta de dados do questionário "Pesquisa Acadêmica sobre Transformação Digital entre as Artesãs", que contou com 27 respostas, analisou-se o Perfil Social das respondentes, verificando-se que o perfil da turma é o seguinte: A faixa de idade predominante das artesãs é de 35 a 
45 anos (33,3\%), seguido de 45 a 55 anos (29,6\%). 40,7\% das artesãs dizem se identificar com a cor parda, seguido de $33,3 \%$ que se dizem brancas e $25,9 \%$ pretas. Mais da metade da turma possui ensino médio completo $(59,3 \%)$ e a faixa de rendimento mensal indica que a maioria das artesãs pertence à classe $E(55,6 \%)$, seguida da classe $D(44,4 \%)$.

Já o Perfil Digital nos mostra que a imensa maioria das artesãs participa das atividades da Escola pelo celular (88,9\%), sendo que 40,7\% das alunas precisou investir algum tipo de aporte financeiro, seja para comprar algum aparelho ou contratar pacote de internet para acessar os conteúdos da Escola de Negócios das Artesãs.

Em um terceiro momento, mensuramos a variação no percentual de percepção da aceleração da transformação digital, por parte da artesã, a partir de 10 critérios. A artesã respondia à seguinte questão: "Pensando em janeiro de 2020, em uma escala de 01 a 03 sendo: 1 - menos verdadeiro e 03 - mais verdadeiro, o quanto você considera que concorda com as sentenças abaixo? "Essa mesma pergunta era repetida considerando o marco comparativo com o mês de junho. Na tabela abaixo, apresentamos os resultados com a variação do percentual, para cada um dos critérios auto avaliados pelas artesãs:

CRITÉRIO AUTO-AVALIADO PELA ARTESÃ V VARIAÇÃO DO

PERCENTUAL

Tenho facilidade em baixar aplicativos

$16 \%$

Sei conectar a Internet no meu aparelho

$-2 \%$

Já assisti Lives em Redes Sociais

$39 \%$

Já participei de aulas em grupos em aplicativos de

$39 \%$

videoconferências

$65 \%$

Já tive mentorias para o meu negócio à distância

$38 \%$

Já usei aplicativo para assistir vídeoaulas

Já fiz mentoria de Desenvolvimento de Coleção à

$65 \%$

distância 
Já participei de Grupo de Mulheres através de

$39 \%$ videoconferências

Tabela 3: Resultado da Pesquisa Acadêmica sobre a Transformação Digital entre as Artesãs Fonte: Autoria Própria

Percebe-se que as mentorias (65\%) para o acompanhamento da aplicação dos conteúdos assistidos na Escola foram a grande novidade nesse processo de aceleração digital. Em segundo lugar, a participação das alunas em encontros específicos da Escola (aulas) e da Liderança Empreendedora (grupo de mulheres), em grupos, utilizando os aplicativos de videoconferências e suas respectivas participações em lives temáticas com conteúdos complementares, pontuou 39\%. Algumas artesãs experimentaram, pela primeira vez, alguns benefícios do mundo digital, seja baixando o primeiro aplicativo para assistir vídeoaulas (38\%), seja se lançando no mundo do e-commerce, criando a rede social da sua marca (31\%) ou, ainda, realizando algum esforço no sentido de participar de uma feira online (27\%). Apenas $16 \%$ das artesãs percebeu uma maior facilidade em baixar aplicativos, após participar dos encontros da Escola e algumas delas $(-2 \%)$, por terem trocado de aparelho durante o período analisado, afirmaram que ainda possuem dificuldades em conectar a internet no seu aparelho.

Analisando-se esta tabela, de um modo geral, compreende-se que letramento digital ainda é um grande desafio a ser trabalhado com este perfil de artesãs que, apesar de estarem se desafiando a aprender, diariamente, ainda possuem suas limitações, isto porque, de acordo com MILL E SANTIAGO (2016. p.12):

(...) o letramento digital requer o desenvolvimento de outras estruturas cognitivas que são bastante complexas. As estruturas mentais típicas do letramento digital pressupõem dominar as tecnologias mais recentes em prol da própria aprendizagem e, também, fazer uso social dessas tecnologias. Ademais, as TDIC carregam consigo grande potencial para a inclusão, pois são amplas as suas potencialidades de veicular o conhecimento entre pessoas ou grupos, seja em termos comunicacionais ou de disponibilidade. (MILL \& SANTIAGO, 2016, p.12)

Por fim, na última etapa do questionário, "considerações gerais", solicitamos às artesãs que descrevessem em uma palavra (para cada aspecto), quais eram os pontos mais positivos e negativos desta Escola estar acontecendo exclusivamente no modelo online, bem como quais foram as principais oportunidades e ameaças que esta experiência de transformação digital às proporcionou.

De um modo geral, as principais forças desse modelo digital apontam para a possibilidade de "aprendizado" que o formato trouxe: aprender a aprender, se desafiando e quebrando barreiras, seguido de "conhecimento", que foi o segundo 
termo mais utilizado. Por outro lado, as principais fraquezas deste modelo englobam, em sua grande maioria, aspectos sócio emocionais desta adaptação em plena pandemia, com as artesãs sentindo falta das interações presenciais, de estarem agrupadas presencialmente (mais de $50 \%$ das respostas contemplam este aspecto), seguido de falhas e falta de suporte técnico na região, com relação à rede de internet insatisfatória.

Quanto aos fatores externos, percebe-se que as principais oportunidades percebidas pelas artesãs, neste modelo digital, são bem similares com o que elas perceberam como "forças", sendo que as palavras "aprendizado" e "conhecimento" voltaram a aparecer várias vezes. Mas algumas respostas se destacam como, por exemplo, a possibilidade de "continuidade"/ "retorno" de execução das aulas pelo fato de o modelo pedagógico ter migrado para o online e, para que isto fosse viável, a "superação" que a turma precisou acessar ao se adaptar tão rapidamente. Por fim, as principais ameaças deste modelo passam por aspectos como infraestrutura insuficiente, com as questões de internet insatisfatória conforme mencionado anteriormente. Novamente, elas sinalizaram um certo receio/insegurança iniciais, ao se lançarem no processo de aceleração digital, que é compreendido enquanto um fator interno.

Compilamos as respostas abertas das artesãs em uma Matriz SWOT, que ilustra suas respectivas percepções sobre a experiência com a aceleração digital na Escola, como um todo (tabela 4).

\begin{tabular}{ccc} 
& FORÇA & \\
& ARAQUimo & Distanciamento \\
& Me empenhar mais em publicar meu trabalho & Tempo \\
na internet & Horário \\
Conhecimento & Internet \\
& Aprendizagem & Dificuldades \\
& Oportunidade & \\
CATORES INTERNOS & Demunicação & \\
& Modicação & \\
& Crescimento & \\
& Praticidade & \\
\hline
\end{tabular}

OPORTUNIDADES

AMEAÇAS 
Conhecimento

Fazer o Instagram e o Facebook da minha

FATORES EXTERNOS marca

Superação

Aprendizado

marca
Superação
Aprendizado
Continuidade
Interação
Autoconhecimento

Ter minha logomarca que eu nunca pensava em ter

\author{
Não dar conta de todos os \\ exercícios \\ Insegurança \\ Tecnologia \\ Internet ruim \\ Medo \\ Isolamento \\ Distração
}

Crescer profissionalmente

Tabela 4: Matriz Swot feita a partir de respostas da Pesquisa sobre a Transformação Digital entre as Artesãs

Fonte: Autoria própria

\section{CONSIDERAÇÕES FINAIS}

Após a investigação dos dados e os resultados apresentados, conclui-se, de modo geral, que a aceleração da transformação digital para as artesãs atendidas na Escola de Negócios tem sido benéfica no sentido de inclusão e colaboração em uma nova era. Ao aceitarem o desafio de migrarem o formato dos encontros presenciais para o digital, estas mulheres de meia idade, moradoras de uma pequena cidade do interior do Estado do Rio, em sua maioria apenas com ensino médio completo e contra todas as dificuldades encontradas com as limitações de uma rede de apoio ineficiente (seja ela social, infraestrutura ou de políticas públicas locais), demonstraram um alto poder de resiliência e inovação, a partir do autoconhecimento que este processo de transformação digital tem possibilitado. Elas se destacam em meio a um cenário onde, por exemplo, muitos empresários de grande porte não acessaram tais características transformadoras com toda esta crise causada pela Pandemia.

Como diria O'BRIEN apud SCHARMER $(2018$, p.7): "the success of an intervention depends on interior conditions of the intervener." E neste ponto, as artesãs da Escola demonstram uma sede de aprendizado e de inovação, constantes, é algo a se destacar.

No entanto, este estudo não tem a pretensão de esgotar o assunto e, por ser uma metodologia ainda em co-construção, considera-se que existe a necessidade de se continuar investigando e acompanhando os processos de transformação digital da Escola, a partir de novos estudos, que serão mais conclusivos ao final do processo com a turma, nos próximos três meses. São tempos de macro transição, de ressignificação estrutural, de repensar comportamentos, culturas, sociedade e economia. Obviamente o segmento do Artesanato sofre o impacto, a partir do momento em que a compra de produtos artesanais não se configura como uma necessidade de base.

No entanto, em uma nova era (não muito distante), CAPRA e HENZEL (2020) nos confortam com uma promessa preditiva de que, possivelmente, dentro de 30 anos, estaremos presenciando o milagre da transformação e da valorização do feito à mão. 
Enquanto esta realidade não se concretiza, seguimos por aqui, cristalizando intenções, trabalhando o poder da visão nestas empreendedoras do feito à mão, desenvolvendo seus processos de letramento digital, de modo que micro revoluções como estas sejam tangibilizadas através de uma Educação, cada vez mais Digital, Empreendedora, Inclusiva e, consequentemente, transformadora de realidades.

\section{REFERÊNCIAS BIBLIOGRÁFICAS}

CAPRA, F e HENDERSON, H. "Pandemics: Lessons looking back from 2050" by Fritjof Capra and Hazel Henderson. Disponível em: https://www.ethicalmarkets.com/pandemics-lessons-looking-back-from-2050/ Acesso em 14 de Junho de 2020

CA TECHNOLOGIES. Accelerating Velocity and Customer Value With Agile and Devops. Disponível em: https://docs.broadps-research-papercom.com/doc/acceleratingvelocity-and-customer-value-with-agile-and-devo. Acesso em 14 de Junho de 2020

FEIRAS DO BRASIL. FINCC 2020: conectando 35 países, promove capacitações e reúne 191 empreendedores em rodadas de negócios. Disponível em: http://www.feirasdobrasil.com.br/revista.asp?area=noticias\&codigo=65933. Acesso em 14 de Junho de 2020.

FORUM FASHION REVOLUTION. O Design e a Educação Empreendedora: um estudo de caso sobre a valorização do saber artesanal. Disponível em: https://www.fashionrevolution.org/wp-content/uploads/2019/10/FR-forum2019ebook.pdf Acesso em 13 de Junho de 2020

LIMEIRA, T. Negócios de impacto social / Tania Maria Vidigal Limeira; Ilustração de Pedro Luna. - 1 ed. - São Paulo: Saraiva Educação, 2018.

MARTINS, R. Pedagogia e andragogia na construção da educação de jovens e adultos. Disponível

em: http://www.seer.ufu.br/index.php/reveducpop/article/view/20331/12520. Acesso em 14 de junho de 2020

MILL, D e SANTIAGO, G. Ambientação e Letramento Digital. São Carlos: Editora Pixel 2016.

PAZ, O. Convergências: ensaios sobre arte e literatura. Tradução de Moacir Werneck Castro. Rio de Janeiro: Rocco, 1991.

REDE ASTA. Relatório de Impacto da Rede Asta em 2019. Disponível em: https://www.redeasta.com.br/case/relatorio-de-impacto-da-rede-asta-em-2019.

Acesso em 13 de Junho de 2020

SCHARMER, O. The Essentials of Theory U: core principles and applications. BerretKoehler Publishers, Inc, 2018. 
SEBRAE. Data SEBRAE - Artesanato. Disponível em: https://datasebrae.com.br/artesanato/Acesso em 13 de Junho de 2020

SEBRAE. Pesquisa Sebrae - O impacto da pandemia do coronavírus nos pequenos negócios - 3a edição. Coleta: 30 de abril a 5 de maio. Disponível em: https://datasebrae.com.br/covid/ Acesso em 13 de Junho de 2020.

SEBRAE. Quer investir no artesanato? Saiba mais sobre esse mercado. Disponível em: http://www.sebrae.com.br/sites/PortalSebrae/ufs/ms/artigos/boletim-comercio-eservicos-artesanato,afb621600576a410VgnVCM1000003b74010aRCRD. Acesso em 10 de Julho de 2019.

SENGE, P. Reintegrating Matter and Mind: The Essence of Systems Thinking in Presencing Institute. Disponível em https://www.youtube.com/watch?v=VZVjedpOulw Acesso em 14 de Junho de 2020. 